\title{
Glioblastoma Multiforme: A Single Hospital Experience
}

\author{
Hamid Behzadnia ${ }^{1}$, Babak Alijani ${ }^{1}$, Mohammadreza Emamhadi ${ }^{2}$, Shahrokh Yousefzadeh-Chabok ${ }^{3}$, \\ Zahra Haghdoost $4^{*}$ \\ ${ }^{1}$ MD, Assistant Professor of Neurosurgery, Neurosurgery Department, Poursina Hospital, Guilan University of Medical Sciences, Rasht, Guilan, \\ Iran \\ ${ }^{2}$ MD, Associate Professor of Neurosurgery, Neurosurgery Department, Poursina Hospital, Guilan University of Medical Sciences, Rasht, Guilan, \\ Iran \\ ${ }^{3}$ MD, Professor of Neurosurgery, Guilan Road Trauma Research Center, Poursina Hospital, Guilan University of Medical Sciences, Rasht, Gui- \\ lan, Iran \\ ${ }^{4}$ MSc in Nursing, Guilan Road Trauma Research Center, Poursina Hospital, Guilan University of Medical Sciences, Rasht, Guilan, Iran
}

*Corresponding Author Address: Guilan Road Trauma Research Center, Poursina Hospital, Guilan University of Medical Sciences, Rasht, Guilan, Iran. Tel: +981333368773, Fax:+981333339842. E-mail: haghdoostzahra@yahoo.com

Article Type: Research Article

Received: October 5, 2015, Last revised: December 29, 2015, Accepted: December 30, 2015

\section{Abstract}

Background \& Aim: Glioblastoma multiforme (GBM), the highest grade glioma (grade IV), is the most malignant form of astrocytoma in adults. This study aimed at evaluating the relationship between demographic, clinical and medical factors with GBM outcome.

Methods \& Materials/Patients: Through a cross-sectional design, 58 patients with newly diagnosed GBM were studied from 1999 to 2015 in Guilan province (North of Iran). Demographic, clinical and medical data including age, gender, score of Karnofsky Performance Scale (KPS), status at discharge, extent of resection (EOR) and administration of post-operative radio-chemotherapy were recorded in an individual questionnaire. The data were analyzed using chi-square and fisher exact tests.

Results: Of all patients, 35 (60.3\%) cases were men and 23 (39.7\%) were women. Age range (at the time of diagnosis of GBM) was 18-82 years $(54.86 \pm 16.34)$. The most common side and location of tumor were left hemisphere and frontal lobe, respectively. 41 patients $(70.7 \%)$ received total surgical resection. Half of patients were treated with simultaneous post-operative radiation therapy and chemotherapy. 11 $(19 \%)$ of all cases died. About $41(70.6 \%)$ of patients demonstrated KPS 50-70.

Conclusion: GBM is a frequent malignant brain tumor with male predominance and high occurrence in age range of $\geq 50$ years. The number of dead patients increases with decreased KPS. Total surgical resection followed by concomitant radiation therapy and chemotherapy were common standard therapeutic regimens.

Keywords: Glioblastoma Multiform; Extent of Resection; Radiotherapy; Chemotherapy

Please cite this paper as: Behzadnia H, Alijani B, Emamhadi M, Yousefzadeh-Chabok Sh, Haghdoost Z. Glioblastoma Multiforme: A Single Hospital Experience. Iran. J. Neurosurg. 2015;1(3):16-20.

\section{Introduction}

Tumors which arise from the glia are called "glioma". Astrocytoma is counted as a type of glioma, arising from the star shape astrocytes. Glioblastoma multiforme (GBM) is the most common malignant astrocytoma in adults that is classified as grade IV glioma. According to World Health Organization (WHO), GBM presents typical properties including high mitotic pleomorphic nuclei, necrotic foci, glomeruloid vascular structures and increased blood vessel in the margin of tumor zone. Grade IV tumor is rapidly growing along with other highly malignant tumors (1). GBM constitutes $30 \%$ of all primary brain tumors (2), $50 \%$ of all primary brain gliomas (3) and $60-75 \%$ of astrocytic tumors (4). About 51 million primary brain tumors are diagnosed in America each year, $36 \%$ of which are glioma; half of them being GBM, with approximately 3 in 100,000 individuals newly diagnosed each year (5). Also ten year's data of National Cancer Registry (NCR) in Iran has reported that primary malignant CNS tumors encompass $2.3 \%$ of all primary malignant tumors. Astrocytoma and glioblastoma together form $60.4 \%$ of the primary malignant registered brain tumors (6). The more the age, the more the incidence of GBM would be (7). Only 3 to 5 percent of patients survive for more than three years, and five years in very rare cases (8-9). Population-based data from the Central Brain Tumor Registry of the United States demonstrated a substantial, almost threefold decrease of one-year survival among patients above the age of 64 years compared with age groups 20-44 years and 45-64 years (10). Considering the exceptionally infiltrative nature of GBM and its proclivity to integrate into normal brain tissue, the treatment process would be hard (11). Preliminary standard therapy including surgical resection, combined radiation and chemotherapy and adjuvant chemotherapy can be considered for removing the remained glioma cells and increasing survival chance (12-13). Since patients with $\mathrm{KPS} \geq 70$ indicated better prognosis than ones with 
KPS $<70$, it should be noted that the level of functional outcome according to KPS plays an important role in determining the degree of prognosis which can guide the clinicians to decide for choosing the appropriate medical therapeutic regimens to remedy GBM sufferers (14-15). This study has two mainstays. First, accurate identifying the epidemiology and treatments which have a major role in outcome and survival. Second, a limited number of studies have been performed on GBM in Guilan province. Thus, this study sought to evaluate the relationship between demographic, clinical and medical factors with GBM outcome.

\section{Methods and Materials/Patients}

A cross-sectional design was adopted to study 58 (50.43\%) patients with newly diagnosed GBM who were referred to neurosurgery department of Poursina Hospital in Rasht from 1999 to 2015. Patients with other types of malignant brain tumor, benign brain tumor, unknown diagnosis and out of this duration were excluded.

Using Hospital Information System (HIS), the collected data were recorded in a pre-designed specific form including demographic (age, gender), clinical (KPS, side and location of tumor, discharge status) and medical (EOR and administration of post-operative radio-chemotherapy). Post-medical treatment KPS scores were categorized as able to work (80-100), unable to work (50-70) and unable to care for self (40 or less) (16).

It is noticeable that quality of tumor resection was accurately assessed by a proficient neurosurgeon via early postoperative CT scan within $24 \mathrm{~h}$ after surgery.

All obtained data were analyzed by SPSS 18 software using chi-square and fisher exact tests. Quality and quantity variables are tabulated as number (\%) and mean $\pm \mathrm{SD}$, successively.

\section{Results}

Of total patients suffering newly diagnosed GBM, 35 (60.3\%) and $23(39.7 \%)$ were men and women, respectively. Age range (at the time of diagnosis of GBM) was 18-82 years (54.86 \pm 16.34$)$. The most common side and location of tumor were left hemisphere and frontal lobe, respectively.

Other affected locations included the frontotemporal, frontoparietal, tempoparietal and parietooccipital lobes with a frequency less than 10 cases for each of them.

In terms of treatment protocols, 41 patients (70.7\%) received total surgical resection. Half of patients were treated with simultaneous post-operative radiation therapy and chemotherapy. No patient received single radiotherapy or single chemotherapy. Functional outcome of patients is based on KPS. Most of patients belonged to alleged category of unable to work $(70.6 \%)$ and $11(19 \%)$ of cases died. Duration of hospitalization in both alive and dead groups were 21.16 (15.94) and 21.13 (20.63), respectively. The patient's characteristics are shown in Table 1.

In the next step, we compared the post-medical treatment KPS score with studied variables. Results indicated that only functional outcome had a significant relationship with KPS score (Table 2).

Our results showed that $11(19 \%)$ of cases died. Only in the KPS variable, a statistically significant difference was observed between alive and dead groups $(\mathrm{P}=0.01)$.
Table 1. Demographic, Clinical and Medical Characteristics in GBM Patients

\begin{tabular}{|c|c|c|c|}
\hline \multicolumn{2}{|c|}{ Variables } & Frequency & Percent \\
\hline \multirow{2}{*}{ Age } & $\geq 50$ & 39 & 67.2 \\
\hline & $<50$ & 19 & 32.8 \\
\hline \multirow{2}{*}{ Gender } & Male & 35 & 60.3 \\
\hline & Female & 23 & 39.7 \\
\hline \multirow{4}{*}{ Side of tumor } & Right & 23 & 39.7 \\
\hline & Left & 25 & 43.1 \\
\hline & $\begin{array}{l}\text { Midline or } \\
\text { Bilatral }\end{array}$ & 2 & 5.2 \\
\hline & Unknown & 7 & 12 \\
\hline \multirow{6}{*}{$\begin{array}{l}\text { Location of } \\
\text { tumor }\end{array}$} & Frontal lobe & 10 & 17.2 \\
\hline & Temporal lobe & 6 & 10.3 \\
\hline & Parietal lobe & 9 & 15.5 \\
\hline & Occipital lobe & 3 & 5.2 \\
\hline & Other & 21 & 36.1 \\
\hline & Unknown & 9 & 15.7 \\
\hline \multirow{3}{*}{$\begin{array}{l}\text { Extent of } \\
\text { resection }\end{array}$} & Total & 41 & 70.7 \\
\hline & Partial & 5 & 8.6 \\
\hline & Unknown & 12 & 20.7 \\
\hline \multirow{3}{*}{$\begin{array}{l}\text { Radiation } \\
\text { therapy }\end{array}$} & Yes & 29 & 50 \\
\hline & No & 28 & 48.3 \\
\hline & Unknown & 1 & 1.7 \\
\hline \multirow{3}{*}{ Chemotherapy } & Yes & 29 & 50 \\
\hline & No & 28 & 48.3 \\
\hline & Unknown & 1 & 1.7 \\
\hline \multirow{2}{*}{$\begin{array}{l}\text { Combine } \\
\text { Chemo-Radio- } \\
\text { therapy }\end{array}$} & Alive & 22 & 46.8 \\
\hline & Dead & 7 & 63.6 \\
\hline \multirow{2}{*}{$\begin{array}{l}\text { Functional } \\
\text { Outcome }\end{array}$} & Alive & 47 & 81 \\
\hline & Dead & 11 & 19 \\
\hline \multirow{3}{*}{$\begin{array}{l}\text { Post-medical } \\
\text { treatment KPS }\end{array}$} & $\begin{array}{l}\text { Able to work } \\
(80-100)\end{array}$ & 3 & 5.2 \\
\hline & $\begin{array}{c}\text { Unable to work } \\
(50-70)\end{array}$ & 41 & 70.6 \\
\hline & $\begin{array}{l}\text { Unable to care } \\
\text { for self }(0-40)\end{array}$ & 14 & 24.2 \\
\hline
\end{tabular}

\section{Discussion}

This study showed a higher number of male than female patients. Most of the patients belonged to subcategory $\geq 50$ age range. Patients' characteristics of this study based on age and sex were incompatible with other studies (13,17-18).

In our study, it was found that in the group that were unable to care for self (KPS $=0-40$ ), the number of patients $\geq 50$ years of age was more than that of patients $<50$ years. Age has been reported as a strong predictor in treatment of patients suffering GBM. Also, age $\geq 50$ years has been introduced as a significant prognostic factor in categorization of GBM, in the RPA of EORTC (European Organization for Research and Treatment of Cancer recursive partitioning analysis) (19). There are several hypotheses to explain the poor clinical outcome of elderly patients. These include increased pre and post-operative 
Table 2. Comparison of Post-medical Treatment Karnofsky Performance Scale Score with Studied Variables

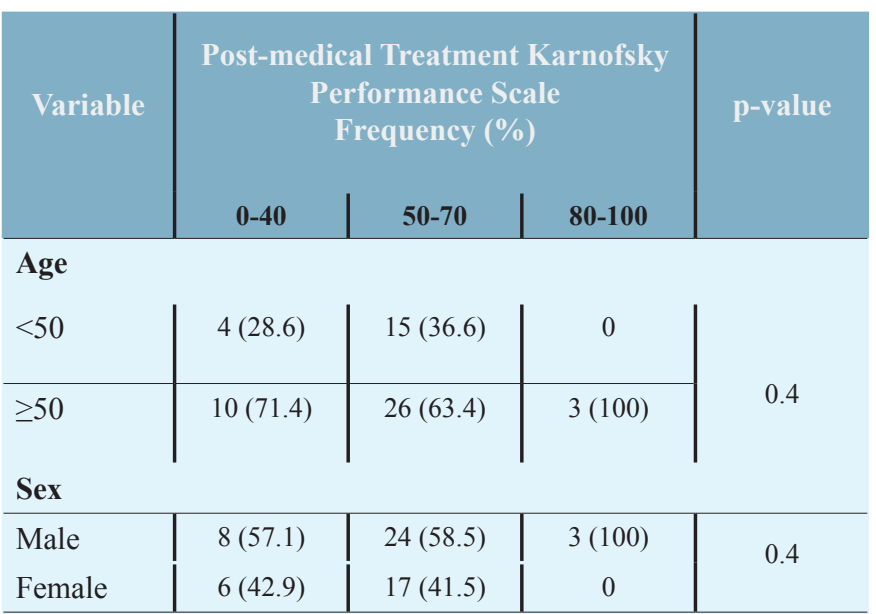

Side of Tumor

\begin{tabular}{l|c|c|c|} 
Right & $4(28.6)$ & $19(48.7)$ & 0 \\
\hline Left & $7(50)$ & $16(41)$ & $2(66.7)$ \\
Two-sided & 0 & $3(7.7)$ & 0 \\
\hline Unknown & $3(21.4)$ & $1(1.8)$ & $1(33.3)$
\end{tabular}

Location of Tumor

\begin{tabular}{l|c|c|c|c}
\hline \begin{tabular}{l|c|c|} 
Frontal \\
Temporal
\end{tabular} & $1(7.1)$ & $8(19.5)$ & $1(33.3)$ & \multirow{2}{*}{0.6} \\
\hline Parietal & $3(21.4)$ & $6(14.6)$ & 0 & \\
Unknown & $3(21.4)$ & $5(12.2)$ & $1(33.3)$ & \\
\hline Others & $7(50)$ & $16(39)$ & $1(1.7)$ & \\
Extent of Resection & $9(100)$ & $32(88.9)$ & 0 & \multirow{2}{*}{0.1} \\
\hline Total & 0 & $4(11.1)$ & $1(100)$ & \\
\hline
\end{tabular}

\section{Radiation Therapy}

\begin{tabular}{l|c|c|c|} 
Yes & $9(64.3)$ & $19(47.5)$ & $1(33.3)$ \\
\hline No & $5(35.7)$ & $21(52.5)$ & $2(66.7)$
\end{tabular}

Chemotherapy

\begin{tabular}{l|l|l|l|l}
\hline Yes & $9(64.3)$ & $19(47.5)$ & $1(33.3)$ & 0.5 \\
No & $5(35.7)$ & $21(52.5)$ & $2(66.7)$ & \\
\hline
\end{tabular}

Functional Outcome

\begin{tabular}{l|c|c|c|} 
Alive & $3(21.4)$ & $41(100)$ & $3(100)$ \\
\hline Dead & $11(78.6)$ & 0 & 0
\end{tabular}

morbidity and mortality and reduced tolerance in therapeutic procedures. In addition, neurodegeneration, resistance to radiotherapy and chemotherapy, different histology, and genetic mutations are also possible reasons for reduced survival (20).

Regarding the side and location of the tumor, left hemisphere and frontal lobe were mostly observed in studied GBM population. Matsuda et al. (2011) investigated 67 newly diagnosed GBM. They found that tumors of left side and frontal lobe possessed a high frequency (19).

Post medical treatment KPS score ranged from 50 to 70 pertaining to the category of unable to work was the most prevalent category of KPS in all patients. Furthermore, all dead patients
Table 3. Reporting Mortality according to Age, Gender, Side, Location, Therapeutic Regimens and KPs Score of the Tumor

\begin{tabular}{|c|c|c|c|}
\hline Variable & Alive & Dead & p-value \\
\hline Age & $\begin{array}{c}55.4(16.7) \\
\mathrm{N}=47\end{array}$ & $\begin{array}{c}52.55(15.22) \\
\mathrm{N}=11\end{array}$ & 0.6 \\
\hline \multicolumn{4}{|l|}{ Sex } \\
\hline Male & $27(57.4)$ & $8(72.7)$ & \multirow{3}{*}{0.3} \\
\hline Female & $20(42.6)$ & $3(27.3)$ & \\
\hline \multicolumn{3}{|c|}{ Side of Tumor } & \\
\hline Right & $20(87)$ & $3(13)$ & \multirow{4}{*}{0.3} \\
\hline Left & $19(76)$ & $6(24)$ & \\
\hline Two-sided & $2(100)$ & 0 & \\
\hline Unknown & $3(60)$ & $2(40)$ & \\
\hline
\end{tabular}

\begin{tabular}{l|c|c|c}
\hline \multicolumn{2}{l|}{ Location of Tumor } \\
Frontal & $9(90)$ & $1(10)$ & \\
\hline Temporal & $6(100)$ & 0 & \multirow{2}{*}{0.6} \\
Parietal & $7(77.8)$ & $2(22.2)$ & \\
\hline Unknown & $7(77.8)$ & $2(22.2)$ & \\
Others & $18(75)$ & $6(25)$ & \\
\hline
\end{tabular}

\begin{tabular}{|c|c|c|c|}
\hline \multicolumn{4}{|c|}{ Chemotherapy } \\
\hline Yes & $22(47.8)$ & $7(63.6)$ & \multirow{2}{*}{0.3} \\
\hline No & $24(52.2)$ & $4(36.4)$ & \\
\hline \multicolumn{4}{|c|}{ Radiotherapy } \\
\hline Yes & $22(47.8)$ & $7(63.6)$ & \multirow{2}{*}{0.3} \\
\hline No & $24(52.2)$ & $4(36.4)$ & \\
\hline
\end{tabular}

Extent of Resection

\begin{tabular}{l|c|c|c} 
Total & $33(86.8)$ & $8(100)$ & 0.2 \\
\hline Sub-total & $5(13.2)$ & 0 &
\end{tabular}

Post-medical Treatment KPS Score

\begin{tabular}{l|c|c|c}
\hline $\begin{array}{l}\text { Able to Work } \\
\text { (80-100) }\end{array}$ & $3(6.4)$ & 0 & \\
$\begin{array}{l}\text { Unable to } \\
\text { Work (50-70) }\end{array}$ & $41(87.2)$ & 0 & 0.01 \\
\hline
\end{tabular}

were in the range of 0-40 (Unable to care for self). In addition to age, level of performance is the most important variable for predicting outcome and survival in GBM patients (21-22). Curran et al. (1993) reported that median survival was 18 months in patients with GBM who were $<50$ years of age and had KPS of 90-100, so that it was only five months in patients with aged $\geq 50$ years with low KPS(23). Lacroix et al. (2001) portrayed the same findings (24). KPS is the most widely used method of quantifying the functional statues of cancer patients (25-26). Mor and colleagues (1984) stated that this tool, when used by trained personnel, can be really valuable for research (27).

Today, maximum possible microsurgical resection followed by concomitant radiation therapy and chemotherapy are common standard multimodal therapy for GBM (28), which was considered in the present study.

In our investigation, most of patients had total surgical resection. In recent decade, abundant evidence has approved that the extent of resection is associated with better outcomes in patients with GBM (29). Sanai et al. (2011) showed that more favorable recovery was obviously achieved in high EOR (30). Margusian also put that survival rate in patients with total 
resection was better than those with subtotal resection or only biopsy (31). Along with these researches, findings of Lacroix et al. (2001) revealed that full resection caused the major effectiveness. First efforts to precisely determine the benefits of survival following microsurgical resection were done by a neurosurgery team in MD Anderson Cancer Center in 2001. According to their study, removing $98 \%$ or most of a tumor significantly increased survival chance (24). The maximum extent of resection depends on the tumor size, shape and location of blood vessels and arteries and sensitive areas of the brain (32).

Our results showed that half of patients received radiotherapy. It is a strong predictive factor in post-operative period. Mineo and colleagues proposed that radiotherapy is a highly notable independent predictor of outcome. Therefore, the average of overall survival rate in the patients undergoing radiotherapy was 16 months versus 13.5 months for those without radiotherapy (33). Other studies have reported analogues results (34-35). Latest studies suggested that diversity of GBM molecular pathology affected the treatment sensitivity. Yount et al. found that ionizing radiation resulted in less cell apoptosis in GBMs with non-functional P53 (36). While GBMs containing wild type gene of P53 were willingly suppressed through apoptotic death by radiation (37). However, p53 gene mutation is common among young GBM patients. This indicates the presence of a correlation between other molecular defects and radiation reaction assessed radiographically in GBM (38). GBM in older patients tends to display the deletion of the tenth chromosome, and it is probable that the genes that are important in terms of radiosensitivity in gliomas are located on this chromosome (39). Some studies have reported ray reactions evaluated optically in malignant glioma patients who manifested favorable performance and underwent total resections (40). These conclusions indicate that radiation therapy has prognostic value in malignant glioma during the post-operative period, confirming the previous findings (34 $35)$.

In the present study, half of patients had chemotherapy in addition to radiation therapy in the post-operation period. First time in an assay it was described that simultaneous TMZ (temozolomide) and radiotherapy increased median survival rates up to $26.5 \%$ within 24 months, a vast improvement over the $10.4 \%$ with radiotherapy alone (41).

Ekici et al. (2013) showed that combined chemotherapy and radiotherapy offered good prognosis with a treatment value (15). In this line, Barker et al. asserted that there was a good outcome in old patients, when TMZ was accompanied to radiotherapy (42).

Present study had some limitations including incomplete available data on some variables, such as side and location of tumor. The small sample size was also another problem which limited out analysis.

\section{Conclusion}

It is generally accepted that GBM is the most common primary brain tumor in adults and the most invasive human tumor. The present study determined that GBM is a frequent malignant brain tumor with male predominance with high occurrence in ages $\geq 50$ years. Mortality rate increases with increased age and decreased KPS. Total surgical resection followed by concomitant radiation therapy and chemotherapy were commonly considered as standard therapeutic regimens.

\section{Acknowledgment}

The authors offer their special thanks to the Clinical Research Development Unit of Poursina Hospital, Guilan University of Medical Sciences, Rasht, Guilan, Iran.

\section{Funding}

None.

\section{Conflicts of Interest}

The authors report no conflict of interest.

\section{References}

1. American Brain Tumor Association. Glioblastoma and Malignant Astrocytoma, Medical Center, Los Angeles, California.pdf.

Available at: www.abta.org/.../glioblastoma-broch.... 2015/12/21

2. Dobes M, Khurana VG, Shadbolt B, Jain S, Smith SF, Smee R, et al. Increasing incidence of glioblastoma multiforme and meningioma, and decreasing incidence of Schwannoma (2000-2008): findings of a multicenter Australian study. Surgical neurology international. 2011; 2:176. doi: 10.4103/2152-7806.90696

3. Stupp R, Mason WP, van den Bent MJ, Weller M, Fisher B, Taphoorn MJ, et al. Radiotherapy plus concomitant and adjuvant temozolomide for glioblastoma. The New England journal of medicine. 2005; 352(10): 987-96. 4. Louis DN, Ohgaki H, Wiestler OD, Cavenee WK, Burger PC, Jouvet A, et al. The 2007 WHO classification of tumours of the central nervous system. Acta neuropathologica. 2007; 114(2): 97-109.

5. CBTRUS: Statistical report: primary brain tumors in the United States, 2000-2004. Central brain tumor registry of the United States, Chicago, 2008. 6. Jazayeri SB, Rahimi-Movaghar V, Shokraneh F, Saadat S, Ramezani R. Epidemiology of Primary CNS Tumours in Iran: A Systematic Review. Asian Pacific Journal of Cancer Prevention. 2013; 14 (6): 3979-3985.

7. Dubrow R, Darefsky AS. Demographic variation in incidence of adult glioma by subtype, United States, 1992-2007. BioMed Central cancer. 2011; 11:325. doi: 10.1186/1471-2407-11-325.

8. Krex D, Klink B, Hartmann C, von Deimling A, Pietsch T, Simon M, et al. Long-term survival with glioblastoma multiforme. Brain : a journal of neurology. 2007; 130: 2596-2606.

9. Deb P, Sharma MC, Mahapatra AK, Agarwal D, Sarkar C. Glioblastoma multiforme with long term survival. Neurology India. 2005; 53(3): 329-332. 10. Ewelt C, Goeppert M, Rapp M, Steiger HJ, Stummer W, Sabel M. Glioblastoma multiforme of the elderly: the prognostic effect of resection on survival. Journal of neuro-oncology. 2011; 103(3): 611-8. doi: 10.1007/ s11060-010-0429-9.

11. Clarke J, Butowski N, Chang SR. Recent advances in therapy for glioblastoma. Archives of neurology. 2010; 67(3): 279-283.

12. Athanassiou H, Synodinou M, Maragoudakis E, Paraskevaidis M, Verigos C, Misailidou D, et al. Randomized phase II study of temozolomide and radiotherapy compared with radiotherapy alone in newly diagnosed glioblastoma multiforme. Journal of clinical oncology : official journal of the American Society of Clinical Oncology. 2005; 23(10): 2372-7.

13. Julka PK, Sharma DN, Mallick S, Gandhi AK, Joshi N, Rath GK. Postoperative treatment of glioblastoma multiforme with radiation therapy plus concomitant and adjuvant temozolomide : A mono-institutional experience of 215 patients. Journal of cancer research and therapeutics. 2013; 9(3): 381-386.

14. Chambless LB, Kistka HM, Parker SL, Hassam-Malani L, McGirt MJ, Thompson RC. The relative value of postoperative versus preoperative Karnofsky Performance Scale scores as a predictor of survival after surgical resection of glioblastoma multiforme. Journal of Neurooncology. 2015; 121(2): 359-64.

15. Ekici MA, Bulut T, Tucer B, Basarslan SK, Kurtsoy A. Prognostic factors in patients with glioblastoma multiforme (clinical research). Turkish Journal of Medical Sciences. 2013; 43: 795-804. doi:10.3906/sag-1204-45

16. Currow DC, Fallon M, Cherny NI, Portenoy RK, Kaasa S. Oxford Textbook of Palliative Medicine. Oxford University Press, 5th Ed, 2015.

17. Kumar N, Kumar P, Angurana SL, Khosla D, Mukherjee KK, Aggarwal R, et al. Evaluation of outcome and prognostic factors in patients of glioblastoma multiforme: A single institution experience. Journal of Neurosciences Rural Practice. 2013; 4(Suppl 1): S46-S55. doi: 10.4103/0976-3147.116455.

18. Laws ER, Parney IF, Huang W, Anderson F, Morris AM, Asher A, et 
al. Survival following surgery and prognostic factors for recently diagnosed malignant glioma: Data from the glioma outcomes project. Journal of Neurosurgery. 2003; 99 (3): 467-73.

19. Matsuda M, Yamamoto T, Ishikawa E, Nakai $\mathrm{K}$, Zaboronok A, Takano S, et al. Prognostic factors in glioblastoma multiforme patients receiving high-dose particle radiotherapy or conventional radiotherapy. The British Journal of Radiology. 2011; 84 (Spec Iss 1): S54-S60. DOI: $10.1259 / \mathrm{bjr} / 29022270$.

20. Brandes AA, Monfardini S. The treatment of elderly patients with high-grade gliomas. Seminars in Oncology. 2003; 30(6 Suppl 19): 77-80.

21. Gundersen S, Lote K, Hannisdal E. Prognostic factors for glioblastoma multiforme-development of a prognostic index. Acta Oncol. 1996; 35: 123-7.

22. Gorlia $\mathrm{T}$, van den Bent MJ, Hegi ME, Mirimanoff RO, Weller M, Cairncross JG, et al. Nomograms for predicting survival of patients with newly diagnosed glioblastoma: Prognostic factor analysis of EORTC and NCIC trial 2698122981/CE.3. The Lancet. Oncology. 2008; 9(1): 29-38.

23. Curran WJ, Scott CB, Horton J, Nelson JS, Weinstein AS, Fischbach AJ, et al. Recursive partitioning analysis of prognostic factors in three Radiation Therapy Oncology Group malignant glioma Trials. J Natl Cancer Inst. 1993; 85: 704 10.

24. Lacroix M, Abi-Said D, Fourney DR, Gokaslan ZL, Shi W, DeMonte F, et al. A multivariate analysis of 416 patients with glioblastoma multiforme: prognosis, extent of resection and survival. Journal of neurosurgery. 2001; 95(2): 190-8.

25. Karnofsky DA, Abelmann WH, Craver LF, Burchenal JH. The use of nitrogen mustards in the palliative treatment of cancer. Cancer. 1948; 1(4): 634-656.

26. Karnofsky DA, Burchenal JH. The clinical evaluation of chemotherapeutic agents in cancer. In: MacLeod CM, ed. Evaluation of Chemotherapeutic Agents. New York: Columbia University Press, 1949, I9 1-205.

27. Mor V, Laliberte L, Morris JN, Wiemann M. The Karnofsky Performance Status Scale An Examination of its Reliability and Validity in a Research Setting. Cancer. 1984; 53(9): 20022007.

28. Carlsson SK, Brothers SP, Wahlestedt C. Emerging treatment strategies for glioblastoma multiforme. EMBO Molecular Medicine . 2014; 6(11): 1359-1370.

29. Sanai N, Berger MS. Glioma extent of resection and its impact on patient outcome. Neurosurgery. 2008; 62(4): 753-766.

30. Sanai N, Polley MY, McDermott MW, Parsa AT, Berger MS. An extent of resection threshold for newly diagnosed glioblastomas. Journal of neurosurgery. 2011; 115(1): 3-8.

31. Margusian R. Survival analysis in patients whit Glioblastoma Multiforme. AMA, 10th edition; 2011.

32. Orringer D, Lau D, Khatri S, Zamora-Berridi $\mathrm{GJ}$, Zhang $\mathrm{K}$, Wu C, et al. Extent of resection in patients with glioblastoma: limiting factors, perception of resectability, and effect on survival. Journal of neurosurgery. 2012; 117(5): $851-859$. 33. Mineo JF , Bordron A, Baroncini M, Ramirez C, Maurage CA, Blond S, et al. Prognosis factors of survival time in patients with glioblastoma multiforme: a multivariate analysis of 340 patients. Acta neurochirurgica. 2007; 149(3):
245-253

34. Filippini G, Falcone C, Boiardi A, Broggi G, Bruzzone MG, Caldiroli D, et al. Prognostic factors for survival in 676 consecutive patients with newly diagnosed primary glioblastoma. Neuro-Oncology. 2008; 10(1): 79-87.

35. Tanaka S, Meyer FB, Buckner JC, Uhm JH, Yan ES, Parney IF. Presentation, management, and outcome of newly diagnosed glioblastoma in elderly patients. Journal of Neurosurgery. 2013; 118(4): 786-98.

36. Yount GL, Haas-Kogan DA, Vidair CA, Haas M, Dewey WC, Israel MA. Cell cycle synchrony unmasks the influence of $\mathrm{p} 53$ function on radiosensitivity of human glioblastoma cells. Cancer research. 1996; 56(3): 500-6.

37. Haas-Kogan DA, Yount G, Haas M, Levi D, Kogan SS, Hu L, et al. p53-dependent G1 arrest and p53-independent apoptosis influence radiobiologic response of glioblastoma. International journal of radiation oncology, biology, physics. 1996; 36(1): 95-103.

38. Louis DN. The p53 gene and protein in human brain tumors. Journal of neuropathology and experimental neurology. 1994; 53(1): 11-21.

39. Leenstra S, Bijlsma EK, Troost D, Oosting J, Westerveld A, Bosch DA, et al. Allele loss on chromosomes 10 and $17 \mathrm{p}$ and epidermal growth factor receptor gene amplification in human malignant astrocytoma related to prognosis. British journal of cancer. 1994; 70(4): 684-9.

40. Wang Y, Li S, Zhang Z, Chen X, You G, Yang $P$, et al. Surgical extent impacts the value of the established prognosticators in glioblastoma patients: a prospective translational study in Asia. Head and Neck Oncology. 2012; 4: 80.

41. Stupp R, Mason WP, van den Bent BM, Weller M, Fisher B, Taphoorn MJ, et al. Radiotherapy plus concomitant and adjuvant temozolomide for glioblastoma. The New England journal of medicine. 2005; 352: 987 - 996.

42. Barker CA, Chang M, Chou JF, Zhang $\mathrm{Z}$, Beal K, Gutin PH, et al. Radiotherapy and concomitant temozolomide may improve survival of elderly patients with glioblastoma. Journal of Neurooncology. 2012; 109(2): 391-7.

\section{Comments}

"Study results of 58 patients hospitalized from 1999 to 2015 in Poursina University Hospital, Rasht, Iran" is the title I choose for the study of my colleagues in Poursina. However, they did not mention even the name of their hospital. They mentioned crosssectional design for their retrospective study of 16 years duration. They wrote about survival of the patients with Glioblastoma multiforme (GBM) in the literature while there is no evidence of their follow-up of patients after three-week hospitalization period. I believe the association of Karnofsky Performance Scale (KPS) and GBM outcome is better understood if we wrote the above-mentioned title. They wrote about many factors such as microscopic evaluation of the GBM tumor, and P75 gene without mentioning of any related results in their own patients. Therefore, we do not see any correlation between their methods, results and discussion. In introduction, they wrote: "About 51 million primary brain tumors are diagnosed in America each year". However, this is onethousand times more than the real data (1). The overall incidence rate for primary brain tumors in USA is 18.1 per 100000 person-years which equals 58,241 patients with GBM based on the US population of $321,773,000$ for 2015 .

Vafa Rahimi-Movaghar, MD, Professor of Neurosurgery, Research Vice Chancellor of Sina Trauma and Surgery Research Center, Tehran University of Medical Sciences, Tehran, Iran

\section{References}

Porter KR, McCarthy BJ, Freels S, Kim Y, Davis FG. Prevalence estimates for primary brain tumors in the United States by age, gender, behavior, and histology. Neuro Oncol. 2010 Jun; 12(6): 520-527. 